\title{
Efficient Removal of Reactive Orange 107 Dye from Aqueous Media by Shrimp Shell Derived Chitosan Functionalized Magnetic Nanoparticles
}

\author{
Tehreem Saba' ${ }^{1}$, Fozia Minhas ${ }^{2}$, Muhammad Imran Malik ${ }^{1}$, Farah Naz Talpur ${ }^{3 *}$, \\ Abdul Jabbar', Muhammad Iqbal Bhanger ${ }^{1}$
}

${ }^{1}$ H.E.J. Research Institute of Chemistry, International Center for Chemical and Biological Sciences (ICCBS), University of Karachi, Karachi, Pakistan

${ }^{2}$ Department of Basic Sciences and Humanities, Khawaja Fareed University of Engineering and Information Technology (KFUEIT), Rahim Yar Khan, Pakistan

${ }^{3}$ National Centre of Excellence in Analytical Chemistry, University of Sindh, Jamshoro, Pakistan

Email: *farahtalpur@hotmail.com

How to cite this paper: Saba, T., Minhas, F., Malik, M.I., Talpur, F.N., Jabbar, A. and Bhanger, M.I. (2018) Efficient Removal of Reactive Orange 107 Dye from Aqueous Media by Shrimp Shell Derived Chitosan Functionalized Magnetic Nanoparticles. American Journal of Analytical Chemistry, 9, 633-653.

https://doi.org/10.4236/ajac.2018.912046

Received: October 31, 2018

Accepted: December 25, 2018

Published: December 28, 2018

Copyright (c) 2018 by authors and Scientific Research Publishing Inc. This work is licensed under the Creative Commons Attribution International License (CC BY 4.0).

http://creativecommons.org/licenses/by/4.0/

cC) (i) Open Access

\begin{abstract}
In present work chitosan functionalized magnetic nanoparticles (CMNPs) were successfully prepared and investigated for the removal of Reactive Orange 107 dye (RO 107) from water. The chitosan was extracted from shrimp shells (Penaeus merguiensis) and was characterized by solubility test and fourier transform infrared spectroscopy (FTIR). Degree of deacetylation of chitosan was examined by ${ }^{1} \mathrm{H}-\mathrm{NMR}$ and potentiometric titration method. Thereafter, the chitosan was used for synthesis of CMNPs. The synthesized CMNPs were characterized by FTIR, scanning electron microscopy-energy dispersive spectroscopy (SEM-EDS), thermal gravimetric analysis (TGA) and atomic force microscopy (AFM). Effects of various variables such as contact time, $\mathrm{pH}$, stirring speed, adsorbent dosage, temperature, and concentration of electrolyte on extraction efficiency were evaluated. Freundlich isotherm model fits better that shows the removal of RO 107 with CMNPs by multilayer adsorption behaviour. Furthermore, kinetic study showed that adsorption process followed pseudo-second order kinetic model regulated by chemisorption. Thermodynamic analysis explained that adsorption of RO 107 onto CMNPs was endothermic as well as spontaneous. The developed CNMPs were applied to environmental remediation of spiked RO 107 treated waste water samples with $96.20 \%$ removal potential, hence, offered an effective sorbent for removal of RO 107 contaminated water samples.
\end{abstract}




\section{Keywords}

Magnetic Nanoparticles, Adsorption, Chitosan Functionalization, Anionic Dyes

\section{Introduction}

Use of dyes is as old as human civilization. Dyes offer fascinating colour to clothing and other stuff. Modern trend of multi-coloured clothing leads to an increasing consumption of dyes that resulted in an augmented amount of polluted water discharged in industrial effluent. A vast majority of dyes are toxic for aquatic biota and humans due to their suspected carcinogenic and mutagenic effects [1] [2] [3] [4].

Dyes are stable, coloured and ionizing aromatic molecules that have ability to bind with substrate. They are resistant to oxidation and aerobic digestion under common conditions of physical and biological treatments, due to their molecular structure [5] [6]. Several methods are used for removal of dyes from water streams including flocculation, membrane separation, photo-catalytic degradation, adsorption, microbial or enzymatic decomposition etc. [6]-[13]. However, most of them are restricted by their high initial and operational costs [14] [15] [16] [17] [18]. Adsorption is considered to be a promising method for such applications because of its ease of operation, simplicity, high recovery, low cost and non-toxic products [19].

Several studies report modification of nanoparticles for preparation of low cost adsorbents for textile dyes and other hazardous materials. Zhu et al. employed magnetic chitosan/polyvinyl alcohol nanoparticles for the adsorption of congo red dye in acidic environment [20]. Magnetic nanoparticles modified with graphene oxide were used for removal of reactive black 5 dye [21]. In another study, removal of reactive red dye was reported with magnetic nanoparticles modified with cetyltrimethyl ammonium bromide from acidic medium [22]. Ghaemi et al. reported on removal of titan yellow dye by employing modified nanoparticles [23]. Activated carbon also proved to be an efficient adsorbent for anionic dyes [24]. Mahmoodi et al. reported removal of several textile dyes by using nanoparticles of titanium oxide [25].

In recent years, applications of nanomaterials for the removal of dyes from water have received increasing attention [26]. Magnetic iron oxide nanoparticles (MNPs) due to their large surface area, high adsorption capacity, and low diffusion resistance are utilized for the removal of dyes as well as other pollutants such as toxic metals from water streams [27] [28] [29]. Surface modification of iron oxide nanoparticles is an effective way to enhance stability, novel properties and possibilities of application. In this context, locally available shrimps ( $P e$ naeus merguiensis) as economical source of chitosan for the synthesis of magnetic $\mathrm{Fe}_{3} \mathrm{O}_{4}$ chitosan nanoparticles $\left(\mathrm{m}-\mathrm{Fe}_{3} \mathrm{O}_{4}-\mathrm{CNs}\right.$ ) followed by study of their 
adsorption properties towards sulphonated anionic dye reactive orange 107, were employed in this study. Various parameters including $\mathrm{pH}$ of the medium, temperature, adsorbent dosage, initial dye concentration on adsorption capacity of the $\mathrm{m}-\mathrm{Fe}_{3} \mathrm{O}_{4}-\mathrm{CNs}$ were thoroughly investigated. In addition, batch adsorption experiments were carried out to study the adsorption kinetics, isotherms and thermodynamics, and a possible adsorption mechanism was also proposed accordingly.

\section{Experimental}

\subsection{Materials}

High-purity grade reagents were used without further purification. Ferric chloride $\left(\mathrm{FeCl}_{3} \cdot 6 \mathrm{H}_{2} \mathrm{O}, 99 \%\right)$ and ferrous chloride $\left(\mathrm{FeCl}_{2} \cdot 4 \mathrm{H}_{2} \mathrm{O}, 98 \%\right)$ were obtained from Merck KGaA, Darmstadt, Germany whereas $\mathrm{NaOH}$ was obtained from UNICHEM, India. Acetic acid, methanol and ethanol were purchased from RCI Labscan Thailand, Sigma Aldrich USA and VWR Chemicals USA, respectively. Reactive orange 107 dye (holactive golden yellow RNL) was obtained from a local supplier. The structure of the dye is presented below as Figure 1. Deionised water with conductivity 0.045 microsiemens $(\mathrm{mS})$ was obtained from a Millipore system.

\subsection{Instrumentation}

A single beam UV spectrophotometer (Shimadzu UV-1800 series spectrophotometer, Kyoto, Japan) with quartz cuvettes having a path length of $1.0 \mathrm{~cm}$ was used to measure the absorbance of samples before and after adsorption experiment in the wavelength range of 190 to $800 \mathrm{~nm}$. A digital pH meter model 510 (Oakton, Eutech, USA) equipped with a reference $\mathrm{Ag} / \mathrm{AgCl}$ electrode and a glass working electrode was used.

FTIR spectra were recorded on a FTIR Bruker Vector 22 spectrometer (Germany). Pallets for FTIR were made by mixing a minute quantity of sample with $\mathrm{KBr}$ and spectra were recorded in the range of $400-4000 \mathrm{~cm}^{-1}$. Ten scans were used to obtain the spectral resolution of $0.1 \mathrm{~cm}^{-1}$.

In order to investigate the size and morphology, scanning electron microscope (SEM) (JED-2300 Analysis Station, JEOL Ltd. Japan) having energy dispersive detector and atomic force microscopy (AFM), Agilent 5500 (Arizona, USA), were employed. Triangular soft silicon nitride cantilever (Veeco, model MLCT-AUHW) with a nominal value of 0.01 and $0.1 \mathrm{~nm}^{-1}$ for the spring constant was used in the tapping mode for all measurements. Samples were prepared by putting a drop of freshly prepared solution on the surface of silicon wafer, and subsequently dried in air.

Proton NMR was recorded on a Bruker AVANCE AN-500 MHz spectrometer. $\mathrm{CDCl}_{3}$ was used as solvent.

Thermal gravimetric analysis was conducted on a SDT Q600 by TA Instruments, USA. The experiments were conducted by using up to $6 \mathrm{mg}$ of the sample 


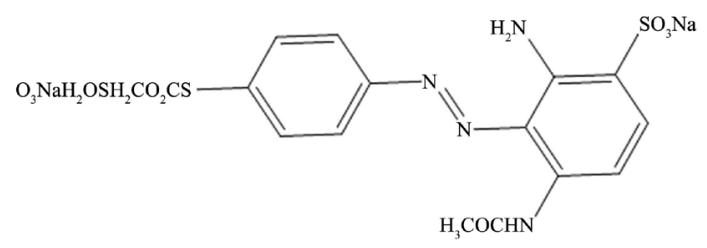

Figure 1. Chemical structure of reactive orange 107 dye.

under nitrogen atmosphere. The thermographs were obtained by heating the samples from $30^{\circ} \mathrm{C}$ to $800^{\circ} \mathrm{C}$ at the rate of $10^{\circ} \mathrm{C}$ permin under nitrogen atmosphere at $50 \mathrm{kPa}$.

\subsection{Extraction of Chitin and Chitosan}

Large quantity of the fresh shrimps (Penaeus merguiensis) was purchased from local market and its waste was collected by separating its head and skin. It was then washed properly with water followed by crushing. The crushed sample was subjected to chemical treatment in order to extract chitin followed by extraction of chitosan. Three steps were followed for the extraction of chitosan. All raw shrimps were treated with $\mathrm{NaOH}$ (1:16) for 48 hrs, followed by filtration and neutralizationfor deproteinization. Demineralization is carried by treating deproteinized sample with $1 \mathrm{M} \mathrm{HCl}(1: 16)$ for $24 \mathrm{hrs}$. The resulting precipitates were filtered and dried after neutralization and can be termed as extracted chitin. Thereafter, the chitin was soaked in $\mathrm{NaOH}$ for $48 \mathrm{hrs}$ at ambient temperature for deacetylation. The final product obtained after washing and drying was chitosan [30].

\subsection{Potentiometric Titration}

Potentiometric titration method was employed to confirm the degree of deacetylation. In a typical process, $0.2 \mathrm{~g}$ of dried chitosan was dissolved in a mixture of $20 \mathrm{~mL}$ of $0.1 \mathrm{M} \mathrm{HCl}$ and $25 \mathrm{~mL}$ of deionized water. As soon as it is dissolved completely, $25 \mathrm{~mL}$ of deionized water was further added into it and allowed to stir for next 30 minutes. Later the solution was titrated against $0.1 \mathrm{M} \mathrm{NaOH}$ solution.

\subsection{Synthesis of CMNPs}

CMNPs were synthesized by slight modifications in a reported method [31]. Briefly, $2 \mathrm{~g}$ of the laboratory made chitosan was allowed to dissolve in $100 \mathrm{~mL}$ of $2 \%$ glacial acetic acid under stirring. An inert environment was created by purging argon gas. The salts of $\mathrm{FeSO}_{4}$ and $\mathrm{FeCl}_{3}$ were added into it in molar ratio of 1:2 as soon as a gel like solution was formed. Solution temperature was raised up to $40^{\circ} \mathrm{C}$. Resulting solution was then allowed to precipitate chemically by the addition of $50 \mathrm{~mL}$ of $30 \% \mathrm{NaOH}$ drop-wise with continuous stirring (final $\mathrm{pH}=$ 10). The suspension was further heated up to $90^{\circ} \mathrm{C}$ and kept on stirring for 2 hours at this temperature. The particles were then cooled and allowed to centrifuge at $8000 \mathrm{rpm}$ for $25 \mathrm{~min}$, after several washing. Particles were finally washed 
with ethanol. Thereafter, particles were dried through freeze drying and were stored for further use.

\subsection{Removal of Reactive Orange 107 on CMNPs}

General procedure of dye removal experiment was as follows. $25 \mathrm{mg}$ of the adsorbent (CMNPs) was mixed with $5 \mathrm{~mL}$ of the dye (RO 107) solution having concentration $50.98 \mathrm{mg} / \mathrm{L}$. Batch experiments were conducted at room temperature to optimize reaction conditions. The flasks were placed in an orbital shaker with varying shaking speed (50 - $250 \mathrm{rpm}), \mathrm{pH}(2-10)$ and time intervals (10 90 minutes) to achieve optimum removal of RO 107. Commercially available buffer solutions having $\mathrm{pH} 2,4,6,8$ and 10 were used to vary the $\mathrm{pH}$ of the dye solution in the range of 2 to 10 in order to evaluate the effect of $\mathrm{pH}$ on adsorption capacity. Effect of adsorbent dosage was evaluated by using five different amounts of CMNPs from 2.5 to $10.0 \mathrm{mg} / \mathrm{mL}$. Effect of stirring speed on adsorption of dye was evaluated by varying it from 50 to $250 \mathrm{rpm}$. The effect of presence of salt in the system was checked by adding $\mathrm{KCl}$ solution of concentrations in the range of $10.0-50.0 \mathrm{mM}$. The absorbance of the solution after adsorption was measured through UV Spectrophotometer at $409.5 \mathrm{~nm}$. For adsorption isotherm studies, RO 107 dye solution with different concentrations ranging from 20.0 to $100.0 \mathrm{mg} / \mathrm{L}$ in temperature range of $30^{\circ} \mathrm{C}$ to $40^{\circ} \mathrm{C}$ were used with $25 \mathrm{mg}$ of CMNPs.

Percentage removal of the dye is calculated by using following formula

$$
\% \text { Removal }=\left[\left(A_{i}-A_{f}\right) / A_{f}\right] \times 100
$$

where $A_{\mathrm{i}}$ is initial absorbance of the dye solution before adsorption and $A_{\mathrm{f}}$ is final absorbance of the dye solution after adsorption.

The amount of dye adsorbed per gram of the nanoparticles was calculated by using the following formula:

$$
q=\left(C_{i}-C_{f}\right) \times V / m
$$

where $q$ is amount of dye adsorbed $(\mathrm{mg} / \mathrm{g}), C_{i}$ is initial concentration of the dye, $C_{f}$ is final concentration of the dye, $V$ is volume of dye solution used (L), and $\mathrm{m}$ is amount of adsorbent used (g).

\subsection{Desorption and Regeneration Studies}

In order to evaluate desorption of the adsorbed dye, dye loaded particles (having $25 \mathrm{mg}$ of dye adsorbed) were desorbed with ethanol solution $(10 \mathrm{~mL})$ containing $\mathrm{NaOH}(5 \mathrm{~mL}, 1 \mathrm{M})$ and placed on orbital shaker for an hour at $250 \mathrm{rpm}$. The absorbance of the solution was measured after an hour to check the percentage of desorption. Subsequently, CMNPs were washed with water and ethanol (three times) and collected using a permanent magnet followed by drying in vacuum at $30^{\circ} \mathrm{C}$ overnight.

The amount of dye desorbed from CMNPs in the solution was calculated by 
using the following formula:

$$
\text { \%Desorption }=\left(A_{f} / A_{i}\right) \times 100
$$

where, $A_{i}$ is the initial absorbance of the dye solution before adsorption and $A_{f}$ is the final absorbance of the dye solution after desorption.

\subsection{Adsorption Isotherms}

Moreover, both Langmuir and Freundlich models were applied at optimized parameters to examine the experimental data. In Langmuir isotherm, monolayer coverage of adsorbate molecules on the homogenous surface of the adsorbent is assumed. Conversely, Freundlich isotherm describes multilayer formation of adsorbate molecules and heterogeneity of the adsorbent surface. The multilayer adsorption process is characterized well with the Freundlich model. The Langmuir and Freundlich isotherm models in linear forms are shown below:

$$
\begin{aligned}
& \left(\frac{C_{e}}{C_{a d s}}\right)=\left(\frac{1}{Q b}\right)+\left(\frac{C_{e}}{Q}\right) \\
& \ln C_{a d s}=\ln A+\left(\frac{1}{n}\right) \ln C_{e}
\end{aligned}
$$

where $C_{a d s}$ is the concentration of adsorbate $\left(\mathrm{mol} \cdot \mathrm{g}^{-1}\right)$ at the adsorbent surface and $C_{e}$ is the concentration of adsorbate in the liquid phase at equilibrium $\left(\mathrm{molL}^{-1}\right)$. The values of constant for Langmuir isotherm i.e. $Q\left(\mathrm{mmol} \cdot \mathrm{g}^{-1}\right)$ and $b$ $\left(\mathrm{L} \cdot \mathrm{mol}^{-1}\right)$ were experimentally obtained from the slope and intercept of the plot of $C_{e} / C_{a d s}$ against $C_{e}$. Similarly, the constants for Freundlich model i.e., $A$ $\left(\mathrm{mol} \cdot \mathrm{g}^{-1}\right)$ and $1 / n$ were achieved from the intercept and the slope of plot $\ln C_{a d s}$ versus $\ln C_{e}$. The amount of the RO 107 adsorbed per unit amount of the adsorbent was correlated using Equation (4) and (5), respectively.

The dimensionless equilibrium constant, $R_{L}$, is characteristic parameter for Langmuir isotherm that can be expressed by the following equation:

$$
R_{L}=1 /\left(1+b C_{i}\right)
$$

where $C_{\mathrm{i}}$ is the initial concentration of the adsorbate $\left(\mathrm{mol} \cdot \mathrm{L}^{-1}\right)$ and $R_{L}$ values explain the favourability $\left(0<R_{L}<1\right)$ of isotherm.

\section{Results and Discussion}

Extraction of Chitosan from shrimp shells is confirmed by its solubility in acids owing to presence of high content of amino groups compared to chitin. Variable degree of deacetylation (DD) of chitin under different experimental conditions is determined by FTIR, proton NMR and potentiometric titrations.

\subsection{Characterization of Extracted Chitosan}

FTIR spectra of extracted chitin and deacetylated chitosan are shown in Figure 2. The prominent absorption bands observed in spectrum of chitosan are at 1652 $\mathrm{cm}^{-1}$ (represent free amine group (N-H) and $2922 \mathrm{~cm}^{-1}, 2868 \mathrm{~cm}^{-1}$ (due to $-\mathrm{NH}$ 
stretching). Absorption bands at $1377 \mathrm{~cm}^{-1}$ represents $-\mathrm{C}-\mathrm{O}$ stretching of primary alcohols $-\mathrm{CH}_{2} \mathrm{OH}$ and $1078 \mathrm{~cm}^{-1}$ represents $\mathrm{C}-\mathrm{O}$ ether group in spectrum of chitosan. The bands at $1560 \mathrm{~cm}^{-1}$ and $1656 \mathrm{~cm}^{-1}$ due to $-\mathrm{N}-\mathrm{H}$ bending of amide in chitin are considerably reduced in chitosan, indicating increased degree of deacetylation. The bands at $3267 \mathrm{~cm}^{-1}$ and $3105 \mathrm{~cm}^{-1}$ which are due to the vibrational mode of - $\mathrm{NH}$ of amide in chitin does not show up in the spectrum of chitosan [32].

Degree of deacetylation was further confirmed by NMR spectroscopy. ${ }^{1} \mathrm{H}-\mathrm{NMR}$ spectrum of the acetylated form i.e. chitin has strong signal at $\boldsymbol{\delta} 2.3$ ppm compared to deacetylated chitosan corresponding to methyl protons, Figure 3(a). Reason for this strong signal is higher ratio of molar content of $\mathrm{N}$-acetylglucosamine in chitin that decreased in chitosan on deacetylation. The peak area of the signal at $\delta 2.3 \mathrm{ppm}$ (methyl) and the sum of areas of anomeric protons i.e. from $\delta 3.6$ to $5.3 \mathrm{ppm}\left(\mathrm{H}_{2}-\mathrm{H}_{6}\right)$ was used from ${ }^{1} \mathrm{H}$-NMR of chitosan for determining DD, (Figure 3(b)) [33].

$$
D D(\%)=\frac{2 A\left(\mathrm{CH}_{3}\right)}{A\left(\mathrm{H}_{2}-\mathrm{H}_{6}\right)} \times 100
$$

The percentage of $D D$ obtained from the Equation (7) was $86.86 \%$.

Degree of deacetylation was further confirmed by potentiometric titrations. The titration curve (Figure 4) with varying $\mathrm{pH}$ showed two inflexion points: the first point $\left(V_{1}\right)$ represents the neutralization of $\mathrm{HCl}$ by the addition of $\mathrm{NaOH}$ while the second point $\left(V_{2}\right)$ corresponds to the neutralization of ammonium ions present in the sample of chitosan.

The amount of amino groups $(D D)$ of chitosan can be calculated by using the difference between two inflexion points i.e. $V_{1}$ and $V_{2}$. The DD through potentiometric titration is calculated by using the following formula [34].

$$
D D(\%)=2.03 \times \frac{V_{2}-V_{1}}{m+0.0042\left(V_{2}-V_{1}\right)}
$$

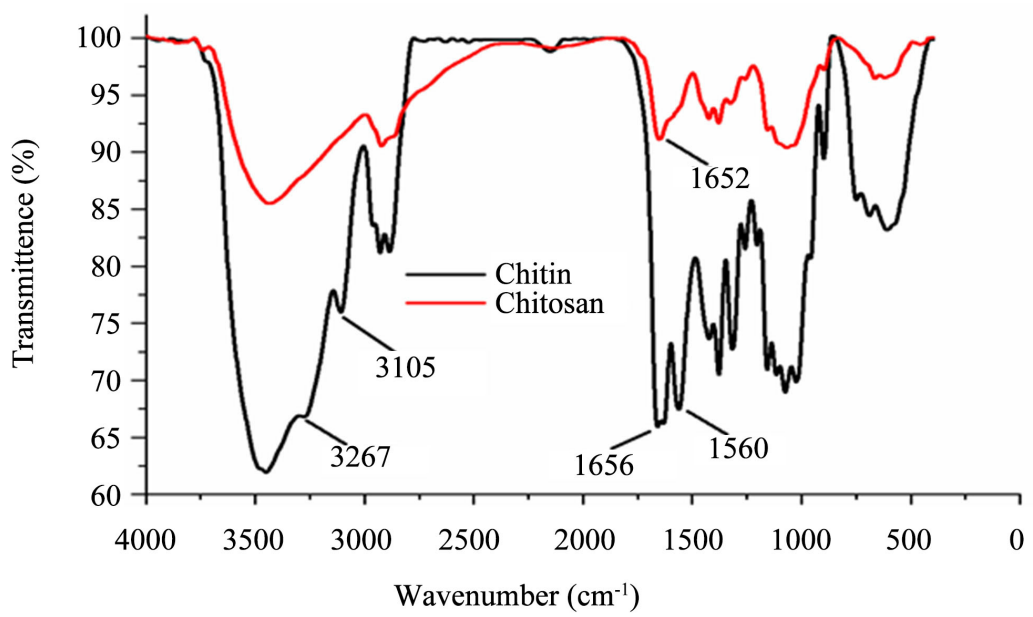

Figure 2. FTIR spectra of chitin and chitosan. 


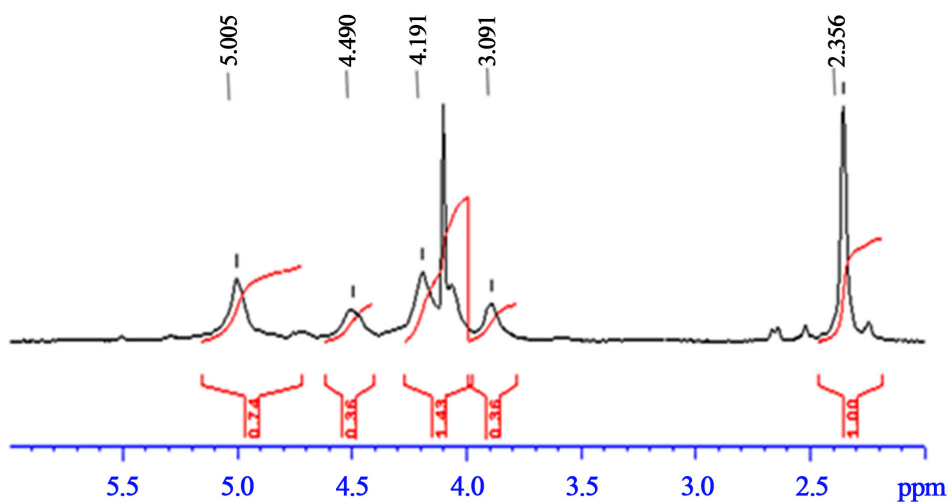

(a)

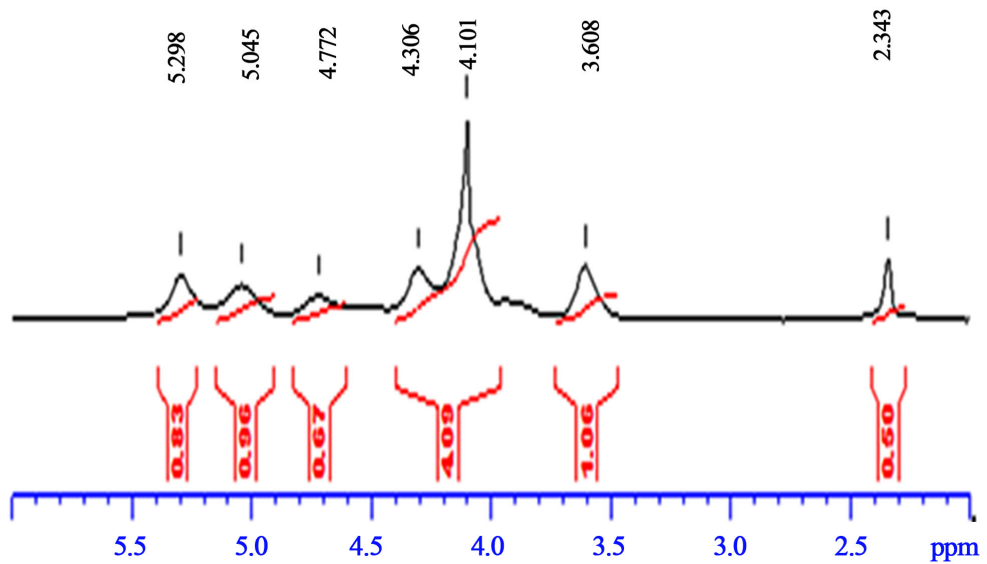

(b)

Figure 3. ${ }^{1} \mathrm{H}-\mathrm{NMR}$ spectra of (a) Chitin (b) Chitosan.

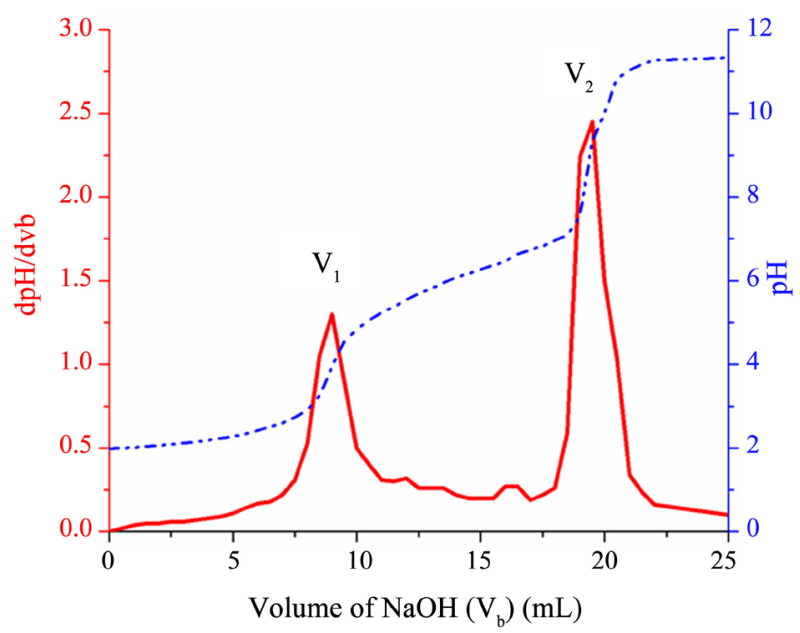

Figure 4. Titration curve showing potentiometric titration of chitosan dissolved in $\mathrm{HCl}$ with $\mathrm{NaOH}$.

where, $V_{1}$ and $V_{2}$ are the volumes of $\mathrm{NaOH}$ used and $\mathrm{m}$ is the mass of chitosan sample, 2.03 is the coefficient obtained from the molecular weight of monomer unit chitin, and 0.0042 is the difference of molecular weight of monomer unit of chitin and chitosan. The value of DD obtained through titration was $87.32 \%$ 
which corresponds well to the result of ${ }^{1} \mathrm{H}-\mathrm{NMR}$.

\subsection{Synthesis of CMNPs}

CMNPs were synthesized by using the method described in experimental section. The $\mathrm{pH}$ of the solution plays vital role during synthesis since acidic media is required for solubilisation of chitosan. Anionic nature of $\mathrm{Fe}_{3} \mathrm{O}_{4}$ induce the electrostatic attraction between these particles and chitosan [35], therefore, chitosan coats on the surface of iron oxide nanoparticlesin alkaline media [36].

FTIR spectra of chitosan, bare magnetic iron oxidenanoparticles (MNPS) and CMNPs were recorded to check the functionalization of chitosan on iron oxide nanoparticles. Figure 5 demonstrate FTIR spectra of MNP, chitosan and CMNP. Spectrum of chitosan contains several peaks corresponding to the presence of multiple functional groups. A strong band at $2922 \mathrm{~cm}^{-1}$ attributes to the presence of $-\mathrm{C}-\mathrm{H}$ bond. A weak band of spectrum at $2868 \mathrm{~cm}^{-1}$ is ascribed for the stretching of methylene groups $-\mathrm{CH}_{2}$ that confirms the presence of chitosan. Absorption band at $1620 \mathrm{~cm}^{-1}$ is due to deformation of biosorption peak of primary amines $\left(-\mathrm{N}-\mathrm{H}_{2}\right)$. Bands identified at $1078 \mathrm{~cm}^{-1}$ represent the stretching vibrations of $\mathrm{C}-\mathrm{O}$ groups. In the spectra of MNPs, the characteristic peak of Fe-O-Fe bond is at $571 \mathrm{~cm}^{-1}$ and a peak at $3413 \mathrm{~cm}^{-1}$ represents the stretching vibration of $\mathrm{OH}$ group. A short absorption band at $458 \mathrm{~cm}^{-1}$ is possibly due to tetrahedral/octahedral sites [37].

FTIR Spectra of CMNP presented in Figure 5 show that the coating with chitosan has changed the spectra of $\mathrm{Fe}_{3} \mathrm{O}_{4}$. The peak of Fe-O-Fe bond is shifted from $571 \mathrm{~cm}^{-1}$ to $567 \mathrm{~cm}^{-1}$.

Appearance of peaks at $2922 \mathrm{~cm}^{-1}$ and $1652 \mathrm{~cm}^{-1}$ are due to the stretching vibrations of $-\mathrm{CH}-$ band and $\mathrm{N}-\mathrm{H}$ bending vibrations of chitosan, respectively. The peak due to N-H bending vibrations is shifted to $1629 \mathrm{~cm}^{-1}$ in CMNP. The absorption band at $3406 \mathrm{~cm}^{-1}$ in CMNP is assigned to vibration of primary amine $-\mathrm{NH}_{2}$ in chitosan. These observations indicate successful binding of chitosan with the magnetic nanoparticles [38] [39].

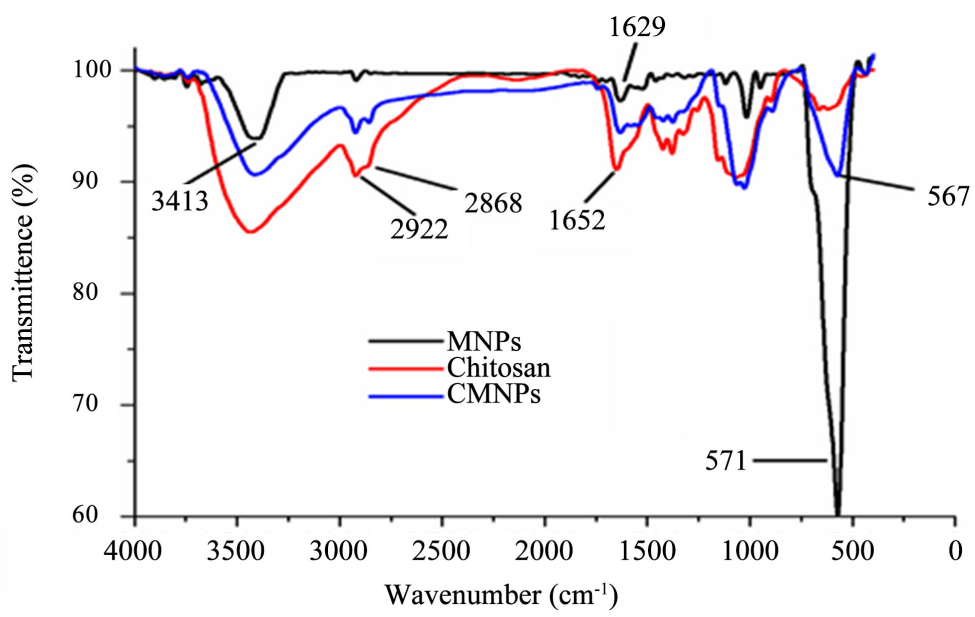

Figure 5. FTIR of MNPs, chitosan and CMNPs. 
SEM images were recorded to see the differences in the surface morphology of magnetic nanoparticles and chitosan functionalized MNPs (Figure 6). These images reveal that MNPs are spherical in shape whereas aggregation of the particles upon treatment with chitosan is induced due to embedment inside the particles. Such molecular polymers exhibit large surface which indicates presence of large number of effective sites at the surface of the particles making it favourable for the adsorption of greater quantities of dyes.

Surface morphology of the CMNPs was studied by atomic force microscopy. It was found that both the particles are spherical in shape, however, size of un-functionalized particles are relatively smaller. The size of the nanoparticles obtained through AFM images was found to be in the range of 25 to $80 \mathrm{~nm}$ (Figure 7).

However, the adsorption properties of MNPs are extensively improved by coating with chitosan. The chitosan is rich with amine functionality that becomes protonated in aqueous environment. Hence, strong hydrogen bonding developed between protonated amines from chitosan and oxygen moiety of sulphonate group of RO 107, resulted in enhancement in the adsorption of RO 107.

Finally, thermal gravimetric analysis of iron oxide particles, chitosan and CMNPs was conducted, Figure 8. The weight loss at different points was observed. The weight loss of MNPs between $30^{\circ} \mathrm{C}$ to $700^{\circ} \mathrm{C}$ was found approximately $8 \%$ with no further degradation. This degradation of particles was due to the loss of moisture and residual water contents from the sample.

Weight loss for chitosan started at lower temperature and continues even beyond $700^{\circ} \mathrm{C}$. Decomposition of the acetylated and deacetylated chains was found between $300^{\circ} \mathrm{C}$ to $400^{\circ} \mathrm{C}$ indicated by steeper weight loss in that region. This continuous degradation of chitosan indicates strong binding forces between polysaccharide units of polymer chains. In case of CMNPs, $11 \%$ weight loss was observed below $200^{\circ} \mathrm{C}$ that is attributed to the removal of moisture content. A significant change in degradation was found between $200^{\circ} \mathrm{C}$ to $550^{\circ} \mathrm{C}$ that corresponds to the breakdown of the chitosan chain covering the surface of iron oxide nanoparticles. No further degradation (weight loss) is noticed beyond this temperature that indicates the presence of $\mathrm{Fe}_{3} \mathrm{O}_{4}$.

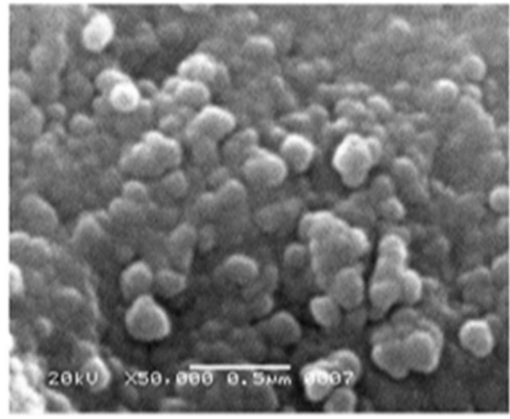

(a)

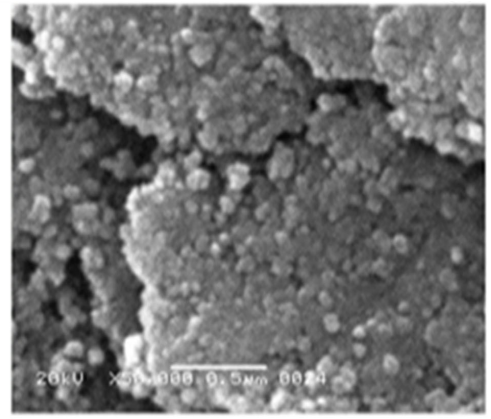

(b)

Figure 6. SEM images of (a) MNPs (b) CMNPs. 


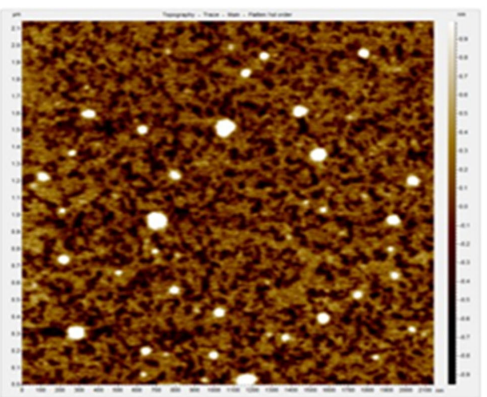

(a)

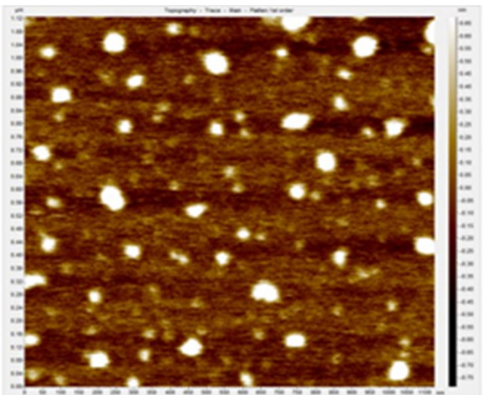

(b)

Figure 7. AFM images of (a) MNPs (b) CMNPs.

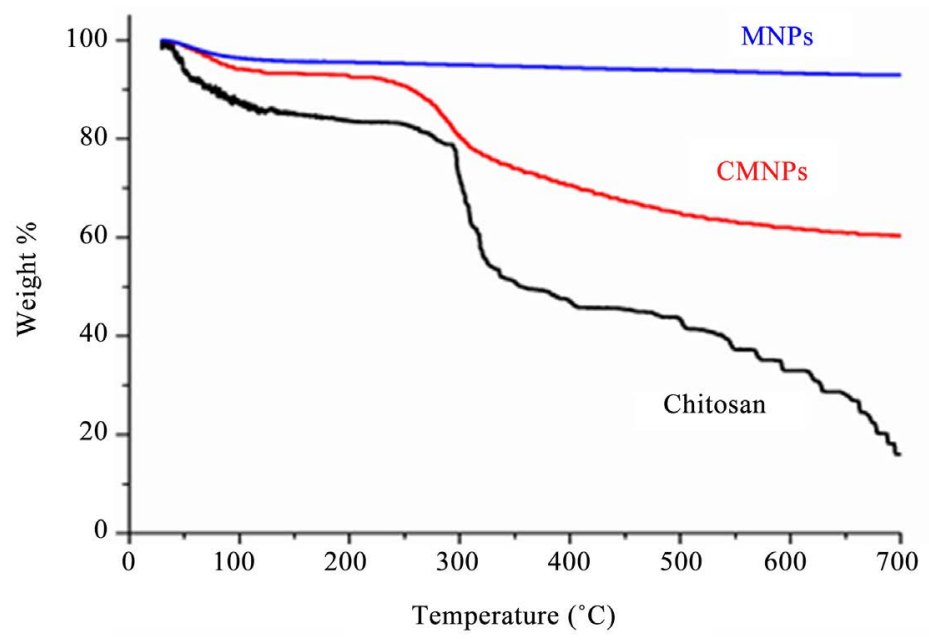

Figure 8. Thermogravimetric profile of (a) MNPs (b) CMNPs (c) Chitosan.

\subsection{Removal of RO 107 by CMNPs}

The removal studies were conducted by using reactive orange 107 dye as adsorbent and CMNPs as adsorbate. FTIR spectra of dye, CMNPs and dye adsorbed CMNPS (DCMNPs) are shown in Figure 9. FTIR of DCMNPs has all the peaks present in the molecule of the dye along with specific peaks of CMNPs. Most of the peaks which were apparent in FTIR spectrum of pure dye due to characteristic absorption of $-\mathrm{OH},-\mathrm{SO}_{3}^{-},-\mathrm{COO}^{-}$and aromatic ring have either reduced in size or have disappeared and the spectrum of DCMNP is dominated by the adsorption bands due to chitosan and MNPs. $\mathrm{NH}_{2}$ group present at the surface of CMNPs get protonated due to acidic environment during adsorption process. On the other hand, sulfonated group of the dye molecule liberate $\mathrm{H}^{+}$ion and become negatively charged. Consequently, electrostatic attraction develops between two counter-ions that resulted in adsorption of dye molecules on the surface of CMNPs.

Various experimental parameters are varied systematically to evaluate their effect on the extraction efficiency of CMNPs for reactive orange 107 dye. A comparison of adsorption of anionic dyes using a variety of adsorbents is presented in Table 1.

It is evident from the literature comparison that the CMNPs have an appreciable adsorption capacity towards RO 107. 


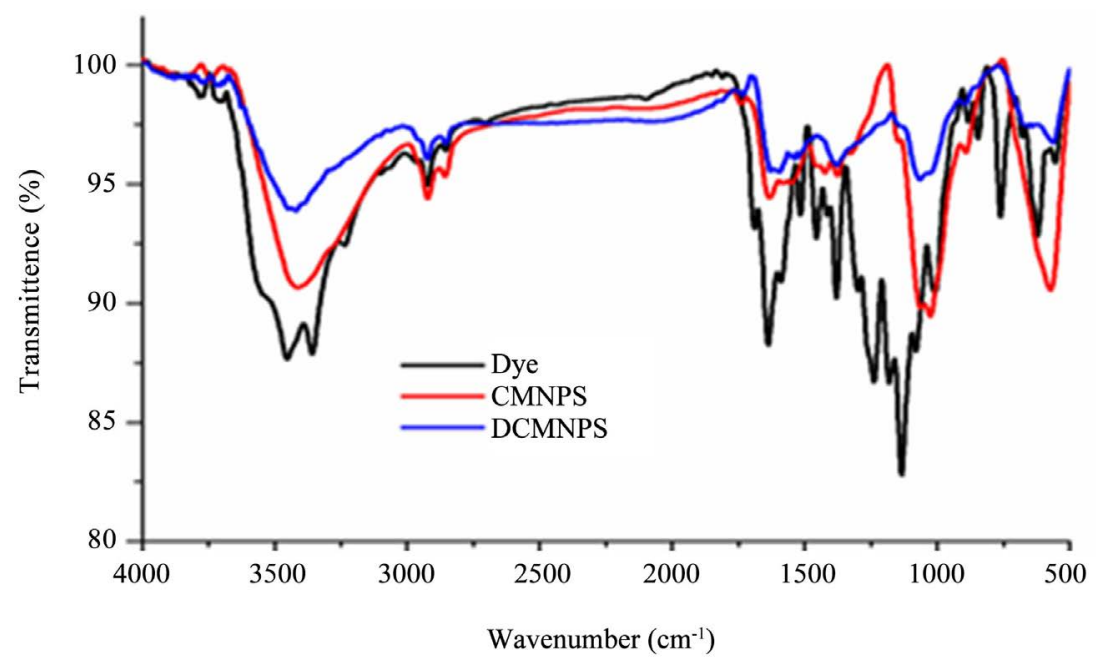

Figure 9. FTIR of Dye, CMNPs and DCMNPs.

Table 1. Comparison of anionic dyes removal by different adsorbents [24] [40] [41] [42] [43].

\begin{tabular}{cccccc}
\hline Adsorbent & Dye & $\mathrm{pH}$ & Isotherm & $\begin{array}{c}\text { Adsorption Capacity } \\
(\mathrm{mg} / \mathrm{g})\end{array}$ & Ref. \\
\hline $\mathrm{NiFe}_{2} \mathrm{O}_{4} \mathrm{NPs}$ & $\begin{array}{c}\text { Eriochrome } \\
\text { Black T }\end{array}$ & 3 & Freundlich & 81.52 & 40 \\
$\begin{array}{c}\text { Magnetic polymer } \\
\text { multi-wall carbon } \\
\text { nanotube }\end{array}$ & Sunset Yellow & 2 & Langmuir & 85.4 & 41 \\
$\begin{array}{c}\text { Polymeric network } \\
\text { surface-modified } \\
\text { magnetic }\end{array}$ & Methyl orange & 5 & Langmuir & 80.5 & 42 \\
$\begin{array}{c}\text { nanoparticles } \\
\text { Fe } \mathrm{O}_{4} \text { magnetic } \\
\text { nanoparticles } \\
\text { modified with } \\
\text { poly-lysine }\end{array}$ & Amaranth & 2 & Langmuir & 90.82 & 43 \\
Carbon & Reactive Black 5 & $<5$ & Langmuir & 23.92 & 24 \\
CMNPs & Reactive Orange & 4 & Freundlich & 95.23 & $\begin{array}{c}\text { Present } \\
\text { 107 }\end{array}$ \\
\hline
\end{tabular}

Dose of adsorbent is one of the prime parameters in the process of adsorption because it decides the capacity of adsorbent for the known concentration of adsorbate at particular conditions. The influence of amount of CMNPs on the adsorption of RO 107 dye is presented in Figure 10(a). Adsorption of the dye increased by increasing the dosage of CMNPs till $25 \mathrm{mg}$ and decreased afterwards. RO 107 becomes accumulated and thereby clogs the active site at high CMNPs dosage. Thus, $25 \mathrm{mg}$ of CMNPs was optimized for further study.

The $\mathrm{pH}$ of solution plays an important role in separation sciences since most of the adsorption processes are $\mathrm{pH}$ dependent. Different solutions at varying $\mathrm{pH}$ were made and investigated at fixed concentration of dye solution for the ad- 
sorption of dye particles onto nanocomposite as a function of $\mathrm{pH}$. The results are presented in Figure 10(b). Evidently the adsorption of dye molecules remains high in acidic medium having maximum adsorption at $\mathrm{pH} 4$ while little or no adsorption was observed in basic environment.

Adsorption of dye molecules was also studied as a function of contact time, Figure 10(c). A steep adsorption was found for first ten minutes. The adsorption does not increase to large extent as a function of contact time beyond 10 minutes.

Stirring speed is one of the important parameters that have pronounced effect on the removal of solute particles. The process was studied at different stirring speeds in order to investigate the distribution of molecules of adsorbent i.e. CMNPs in the solution. The results obtained are demonstrated in Figure 10(d). Adsorption of dye increased with increase in the stirring speed (50 - $250 \mathrm{rpm}$ ). Higher stirring speed results in an increased degree of agitation that leads to more frequent contact of CMNPs with dye molecules.

Salts are often used in different processes. Hence, effect of salt concentration was studied on adsorption efficiency of CMNPs. The presence of $\mathrm{KCl}$ reduced the adsorption efficiency as can be seen in Figure 10(e). Adsorption capacity of CMNPs decreased with increase in the salt concentration. Presence of the salt in a system reduces the electrostatic interaction between CMNPs and dye molecules. The dye used is anionic in nature therefore the anions of the salt compete with these ions that inhibits the process.

At last effect of temperature on the adsorption capacity of dye was checked. It was found that adsorption of dye increased with increase in temperature, Figure 10(f). The increased adsorption of dye with rise in temperature might be due to subsequent increase in internal energy of CMNPs. Temperature apparently accelerates the mass transfer of RO 107 onto the surface of CMNPs.

\subsubsection{Adsorption Isotherms}

The interactive behaviour between the adsorbate and the adsorbent can be explicitly explained by adsorption isotherms. Furthermore, the adsorption capacity of the sorbent can also be determined accurately by means of isotherm data. Therefore, in present study, the adsorption capacity of CMNPs is investigated by performing equilibrium study.

Plots of both Langmuir and Freundlich isotherms provided the linear plots with good regression coefficients $\left(\mathrm{R}^{2}\right)$ values (Table 2 ). In case of Freundlich isotherm model comparatively more linear relation was investigated between $\ln$ $\mathrm{C}_{\text {ads }}$ and $\ln \mathrm{C}_{\mathrm{e}}$, which indicated that Freundlich isotherm model is better fit for the experimental data of RO 107 adsorption. The favourability of the Freundlich isotherm model is also established from the $\mathrm{n}$ values. The Freundlich constant, $\mathrm{n}$ should have values lying in the range of 1 to 10 for classification as favourable adsorption [44]. In present studies for RO 107 dye removal $1 / \mathrm{n}$ value is 2.604 , and it shows that sorption on CMNPs is favourable adsorption procedure. Hence, the multilayer adsorption of the RO 107 on the surface of CMNPS was evident following the Freundlich isotherm model. 

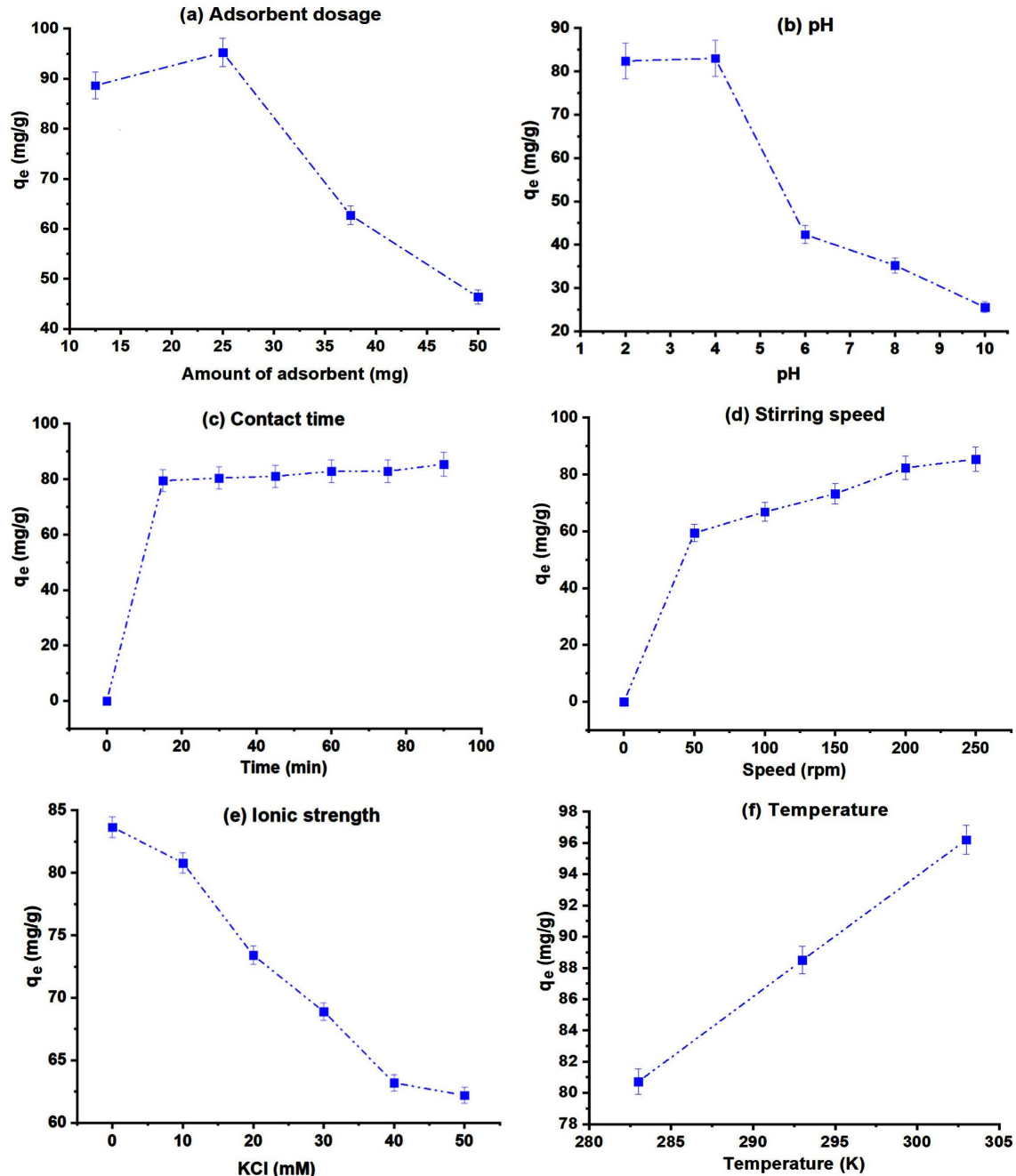

Figure 10. Effect of various experimental variable on the extraction efficiency of CMNPs (a) adsorbent dose, experimental conditions-dye concentration : $9 \times 10^{-5} \mathrm{M}$, shaking time: $90 \mathrm{~min}, \mathrm{~V}: 5 \mathrm{~mL}, \mathrm{pH}$ : 4 , T: $25^{\circ} \mathrm{C}$; (b) $\mathrm{pH}$, experimental conditions-dye concentration: $9 \times 10^{-5} \mathrm{M}$, shaking time: $90 \mathrm{~min}, \mathrm{~V}=5 \mathrm{~mL}$, amount of adsorbent: $25 \mathrm{mg}, \mathrm{T}: 25^{\circ} \mathrm{C}$; (c) Contact time, experimental conditions-dye concentration: $9 \times 10^{-5} \mathrm{M}$, amount of adsorbent: $25 \mathrm{mg}, \mathrm{V}: 5 \mathrm{~mL}, \mathrm{pH}: 4, \mathrm{~T}: 25^{\circ} \mathrm{C}$; (d) Stirring speed, experimental conditions-Co: $50.98 \mathrm{mg} / \mathrm{lit}, \mathrm{pH}: 4$, amount of adsorbent: $25 \mathrm{mg}, \mathrm{V}: 5 \mathrm{~mL}, \mathrm{~T}: 25^{\circ} \mathrm{C}$, Shaking time $10 \mathrm{~min}$ (e) Ionic strength, experimental conditions-Co: $50.98 \mathrm{mg} / \mathrm{lit}, \mathrm{pH}: 4$, amount of adsorbent: $25 \mathrm{mg}, \mathrm{V}: 5 \mathrm{~mL}, \mathrm{~T}: 25^{\circ} \mathrm{C}$, Stirring speed $250 \mathrm{rpm}$, Shaking time $10 \mathrm{~min}$; (f) Temperature, experimental conditions-Co: $50.98 \mathrm{mg} / \mathrm{lit}$, pH: 4, amount of adsorbent: 25 $\mathrm{mg}, \mathrm{V}: 5 \mathrm{~mL}$, Stirring speed $250 \mathrm{rpm}$, Shaking time $10 \mathrm{~min}$.

Table 2. Langmuir and Freundlich isotherm constants for adsorption of RO 107 dye by CMNPs.

\begin{tabular}{ccccccc}
\hline & \multicolumn{2}{c}{ Langmuir } & \multicolumn{3}{c}{ Freundlich } \\
\hline $\mathrm{Q}_{0}$ & $\mathrm{~B}$ & $\mathrm{R}_{\mathrm{L}}$ & $\mathrm{R}^{2}$ & $\mathrm{~A}$ & $1 / \mathrm{n}$ & $\mathrm{R}^{2}$ \\
\hline $\begin{array}{c}2.248 \\
\mathrm{mmolg}^{-1}\end{array}$ & $\begin{array}{c}9.26 \times 10^{4} \\
\mathrm{Lmol}^{-1}\end{array}$ & $0.12-0.41$ & 0.98 & $0.384 \mathrm{mmolg}^{-1}$ & 2.604 & 0.99 \\
\hline
\end{tabular}




\subsubsection{Kinetic Models}

Two kinetic models namely pseudo-first-order and pseudo-second-order were applied in order to investigate the mechanism of adsorption. The adsorption of RO 107 by CMNPs was found to follow both kinetic models. The equation for pseudo-first-order equation to analyse experimental data is represented by

$$
\ln \left(q_{e}-q_{t}\right)=\ln q_{e}-k_{1} t
$$

where $q_{\mathrm{e}}\left(\mathrm{mol} \cdot \mathrm{g}^{-1}\right)$ is the amount of RO 107 adsorbed at equilibrium, $q_{t}\left(\mathrm{~mol} \cdot \mathrm{g}^{-1}\right)$ is the amount of RO 107 adsorbed at time $t$, and $k_{1}\left(\mathrm{~min}^{-1}\right)$ is the adsorption rate constant. Thus, $k_{1}$ values were calculated from the slopes of the plots and are listed in Table 3 for RO 107.

Moreover, experimental data was checked by applying the pseudo-secondorder equation as follows

$$
d q / d t=k_{2}\left(q_{e}-q_{t}\right)^{2}
$$

where $k_{2}\left(\mathrm{gmol}^{-1} \cdot \mathrm{min}^{-1}\right)$ is the rate constant of second-order adsorption under similar conditions. The integration of Equation (10) carried to make it linear form Equation (11)

$$
\left(t / q_{t}\right)=\left(1 / k_{2} q_{e}^{2}\right)+\left(1 / q_{e}\right) t
$$

The values of $q_{e}$ and $k_{2}$ can be determined from the slope and intercept of the plot $t / q_{t}$ versus $t$ in Equation (11) if the second-order kinetics is operative. All the values obtained from these kinetic equations are collected in Table 2. It can be inferred from the values of regression coefficient $\left(R^{2}\right)$ that adsorption in this study follows pseudo-second order equation relatively better than the pseudo-first order equation. The agreement of the experimental data with the pseudo-second order kinetic model indicates that the adsorption of RO 107 dye onto CMNPs regulated by chemisorption (as the rate-limiting step of the adsorption mechanism and no involvement of a mass transfer in solution) involving valence forces through sharing or exchange electrons between adsorbent and adsorbate [45].

Furthermore, the first-order and pseudo-second order kinetic models could not identify the diffusion mechanism. Thus the kinetic results were then analysed via film diffusion or the intraparticle diffusion mechanism by Reichenberg equation as follows

$$
Q=1-\frac{6 \mathrm{e}^{-\beta_{t}}}{\pi^{2}}
$$

Table 3. Comparison of the pseudo-first-order and pseudo-second-order reaction rate constants.

\begin{tabular}{cccccccccc}
\hline \multicolumn{2}{c}{$\begin{array}{c}\text { Pseudo-first-order } \\
\text { kinetic model }\end{array}$} & \multicolumn{2}{c}{$\begin{array}{c}\text { Pseudo-second-order } \\
\text { kinetic model }\end{array}$} & $\begin{array}{c}\text { Reichenberg } \\
\text { Equation }\end{array}$ & $\begin{array}{c}\text { Morris-Weber } \\
\text { Plot }\end{array}$ \\
\hline $\begin{array}{c}\mathrm{K}_{1} \\
\left(\mathrm{~min}^{-1}\right)\end{array}$ & $\begin{array}{c}\mathrm{q}_{\mathrm{e}} \\
\left(\mathrm{mol} \cdot \mathrm{g}^{-1}\right)\end{array}$ & $\mathrm{R}^{2}$ & $\begin{array}{c}\mathrm{K}_{2} \\
\left(\mathrm{~g} \cdot \mathrm{mol}^{-1}\right. \\
\left.\mathrm{min}^{-1}\right)\end{array}$ & $\begin{array}{c}\mathrm{q}_{\mathrm{e}} \\
\left(\mathrm{mol} \cdot \mathrm{g}^{-1}\right)\end{array}$ & $\mathrm{R}^{2}$ & $B_{t}$ & $\mathrm{R}^{2}$ & $\begin{array}{c}R_{\mathrm{d}} \\
\mathrm{molg}^{-1} \\
\mathrm{~min}^{-1 / 2}\end{array}$ & $\mathrm{R}^{2}$ \\
\hline 0.257 & 0.0031 & 0.98 & 4051 & 0.00069 & 0.99 & 0.199 & 0.99 & 0.00014 & 0.99 \\
\hline
\end{tabular}


where $Q=q_{t} / q_{m}, \beta_{t}=\pi^{2} D i / r^{2}, q_{t}$ and $q_{m}$ are concentrations of dye adsorbed at time $t$ and the maximum adsorption capacity and $D_{i}$ is the effective diffusion coefficient of the adsorbate species inside the adsorbate particles. The mathematical function of $Q$ is $\beta_{t}$ that can be determined from this equation

$$
\beta_{t}=-0.4977-\ln (1-Q)
$$

The plot of $\beta_{t}$ against $t$ is linear for RO 107 explained that the rate controlling step for the adsorption is intraparticle diffusion however small fraction of RO 107 also adsorbs via film diffusion because the plot does not pass through origin, Figure 11(a).

Another mathematical form for kinetic adsorption is Morris-Weber equation as shown below

$$
q_{t}=R_{d} \sqrt{t}
$$

where $R_{d}$ is the rate constant of intraparticle diffusion and $q_{t}$ is the concentration of adsorbed dye at time $t$. Linear relationship for adsorption data was observed for the plot of $q_{t}\left(\mathrm{~mol} \cdot \mathrm{g}^{-1}\right)$ versus $\sqrt{t}$, Figure $11(\mathrm{~b})$. The value of rate constant $\left(R_{\mathrm{d}}\right)$ for intraparticle transport comes out to be $0.0014 \mathrm{molg}^{-1} \mathrm{~min}^{-1 / 2}$ with the regression coefficient $\mathrm{R}^{2}$ of 0.99 for $\mathrm{RO} 107$.

\subsubsection{Adsorption Thermodynamics}

Temperature has huge impact on adsorption therefore influence of temperature on the adsorption of RO 107 by CMNPs was examined. It has been observed that rise in temperature increases the adsorption capacity $\left(\mathrm{q}_{\mathrm{e}}\right)$. All thermodynamic parameters including Gibbs free energy $\Delta G\left(\mathrm{~kJ} \cdot \mathrm{mol}^{-1}\right)$, entropy $\Delta S\left(\mathrm{~kJ} \mathrm{~mol}^{-1} \cdot \mathrm{K}^{-1}\right)$ and enthalpy $\Delta H\left(\mathrm{~kJ} \cdot \mathrm{mol}^{-1}\right)$ were determined by applying following equations

$$
\begin{gathered}
\ln K c=\frac{-\Delta H}{R T}+\frac{\Delta S}{R} \\
\Delta G=-R T \ln K c
\end{gathered}
$$

where $R$ is the gas constant and $K_{c}$ is adsorption equilibrium constant.

The obtained values of $\Delta \mathrm{H}$ and $\Delta \mathrm{S}$ were $44.1 \mathrm{~kJ} \cdot \mathrm{mol}^{-1}$ and $0.158 \mathrm{~kJ} \cdot \mathrm{mol}^{-1} \cdot \mathrm{K}^{-1}$, respectively. The obtained values for $\Delta \mathrm{G}$ at 283,293 and $303 \mathrm{~K}$ were $-1.77(\ln K c=$ $0.753),-3.23(\ln K c=1.324)$, and $-5.02(\ln K c=1.992)$, respectively. It can be inferred from positive and negative values of $\Delta H$ and $\Delta G$ that adsorption process for $\mathrm{RO} 107$ is endothermic and spontaneous. Moreover, $K_{c}$ values increased with rise in temperature and increased randomness at the solid/solution interphase during the adsorption process is suggested by slightly positive $\Delta S$ values.

\subsubsection{Desorption of Dye and Recycling of CMNPs}

Desorption of adsorbed dye molecules from CMNPs was studied with two different eluents (ethanol, and $1 \mathrm{M} \mathrm{NaOH}$ aqueous solution) and their binary mixture (1:1). Ethanolic $\mathrm{NaOH}$ proved to be better desorbing agent compared to ethanol and $\mathrm{NaOH}$, having $98 \%$ desorption potential. The adsorption/ desorption cycle was repeated three times to evaluate the reusability of CMNPs. The 


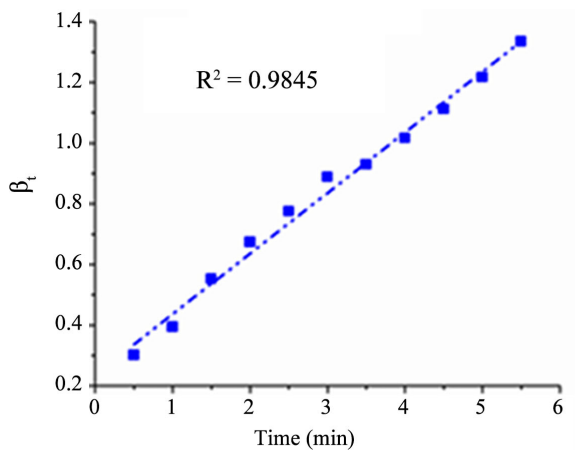

(a)

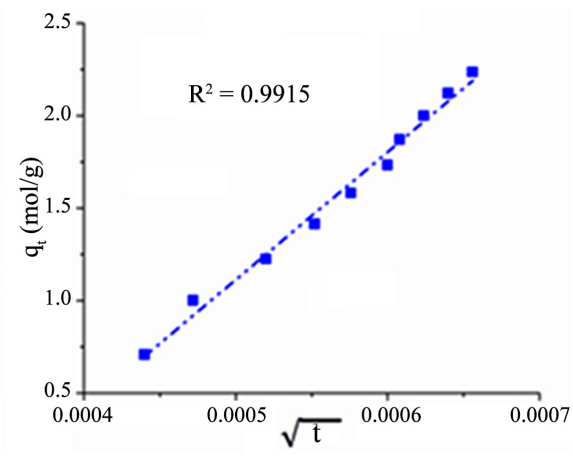

(b)

Figure 11. Diffusion models for adsorption of RO 107 on CMNPs. (a) Reichenbery plot; (b) Moris Weber plot.

results demonstrate reasonably maintained desorption for three consecutive cycles that is $98 \%, 94 \%$ and $90 \%$. Hence CMNPs maintained $90 \%$ adsorption potential after three consecutive cycles and can be used repeatedly as an efficient adsorbent for practical wastewater treatment.

\subsection{Environmental Remediation}

CMNP's were applied for the removal of RO 107 dye from a combined effluent treatment plantwater sample collected from Korangi Industrial Area, Karachi (Pakistan), in order to verify their suitability for environmental application. The RO 107 concentration in the treated wastewater sample was below than the LOD of the UV-Vis instrument; therefore, the treated wastewater sample was spiked with RO 107 to achieve a final concentration of $50.98 \mathrm{mg} / \mathrm{L}$. CMNPs $(25 \mathrm{mg}$ ) were added to $10 \mathrm{~mL}$ of spiked waste water sample and left for 60 minutes in orbital shaker at $250 \mathrm{rpm}$. The results showed that $96.20 \%$ of the RO 107 was removed from the spiked treated wastewater, demonstrating the application of CMNP's for contaminated real water samples.

\section{Conclusion}

In this study, chitosan functionalized magnetic (iron oxide) nanoparticles were successfully prepared and investigated for removal of an anionic dye RO 107 from water. The degree of deacetylation of chitosan as obtained by ${ }^{1} \mathrm{H}-\mathrm{NMR}$ and potentiometric titration method was found to be over $70 \%$. The MNPs were characterized by XRD, FTIR, AFM, TG/DTA. The synthesized nanoparticles exhibit spherical shape and their size was in the range of $50-70 \mathrm{~nm}$. The nanocomposite efficiently removed the anionic dye under acidic conditions at $\mathrm{pH} 4$ via chemical interactions between RO 107 anions and the amine group of chitosan. The adsorption isotherms favourably followed Freundlich as compared to Langmuir isotherm. The kinetic model analysis revealed that pseudo-second-order rate equation is operative for the adsorption of RO 107 on CMNPs. The adsorption of RO 107 onto CMNPs was thermodynamically favorable, spontaneous and endothermic in nature. The adsorption capacity of the 
CMNP's was $95.23 \mathrm{mg} / \mathrm{g}$ for RO 107. The reported CMNPs successfully removed spiked RO 107 dye from real industrial effluent. Hence, unique properties of CMMNP's make it a substitute to traditional coagulants in wastewater treatment.

\section{Conflicts of Interest}

The authors declare no conflicts of interest regarding the publication of this paper.

\section{References}

[1] Özcan, A.S. and Özcan, A. (2004) Adsorption of Acid Dyes from Aqueous Solutions onto Acid-Activated Bentonite Journal of Colloid and Interface Science, 276, 39-46.

[2] Hai, F.I., Yamamoto, K. and Fukushi, K. (2007) Hybrid Treatment Systems for Dye Wastewater. Critical Reviews in Environmental Science and Technology, 37, 315-377. https://doi.org/10.1080/10643380601174723

[3] Novotný, Č., Dias, N., Kapanen, A., Malachová, K., Vándrovcová, M., Itävaara, M. and Lima, N. (2006) Comparative Use of Bacterial, Algal and Protozoan Tests to Study Toxicity of Azo- and Anthraquinone Dyes. Chemosphere, 63, 1436-1442. https://doi.org/10.1016/j.chemosphere.2005.10.002

[4] Ohe, T., Watanabe, T. and Wakabayashi, K. (2004) Mutagens in Surface Waters: A Review. Mutation Research/Reviews in Mutation Research, 567, 109-149. https://doi.org/10.1016/j.mrrev.2004.08.003

[5] Gholivand, M.B., Yamini, Y., Dayeni, M. and Seidi, S. (2015) Removal of Methylene Blue and Neutral Red from Aqueous Solutions by Surfactant-Modified Magnetic Nanoparticles as Highly Efficient Adsorbent. Environmental Progress \& Sustainable Energy, 34, 1683-1693. https://doi.org/10.1002/ep.12174

[6] Sun, Q. and Yang, L. (2003) The Adsorption of Basic Dyes from Aqueous Solution On Modified Peat-Resin Particle. Water Research, 37, 1535-1544. https://doi.org/10.1016/S0043-1354(02)00520-1

[7] Gupta, V. (2009) Application of Low-Cost Adsorbents for Dye Removal-A Review. Journal of Environmental Management, 90, 2313-2342. https://doi.org/10.1016/j.jenvman.2008.11.017

[8] Reed, B.E., Matsumoto, M.R., Jensen, J.N., Viadero, R. and Lin, W. (1998) Physicochemical Processes. Water Environment Research, 70, 449-473. https://doi.org/10.2175/106143098X134208

[9] Ravi Kumar, M., Rajakala Sridhari, T., Durga Bhavani, K. and Dutta, P.K. (1998) Trends in Color Removal from Textile Mill Effluents. Colourage, 45, 25.

[10] Garg, V., Kumar, R. and Gupta, R. (2004) Removal of Malachite Green Dye from Aqueous Solution by Adsorption Using Agro-Industry Waste: A Case Study of Prosopis Cineraria. Dyes and Pigments, 62, 1-10. https://doi.org/10.1016/j.dyepig.2003.10.016

[11] Murray, C. and Parsons, S. (2004) Advanced Oxidation Processes: Flowsheet Options for Bulk Natural Organic Matter Removal. Water Science \& Technology, 4, 113-119. https://doi.org/10.2166/ws.2004.0068

[12] Bessbousse, H, Rhlalou, T., Verchère, J.-F. and Lebrun, L. (2008) Removal of Heavy Metal Ions from Aqueous Solutions by Filtration with a Novel Complexing Membrane Containing Poly(Ethyleneimine) in a Poly(Vinyl Alcohol) Matrix. Journal of 
Membrane Science, 307, 249-259. https://doi.org/10.1016/j.memsci.2007.09.027

[13] Chaudhary, A.J. and Grimes, S.M. (2001) Simultaneous Recovery of Copper and Degradation of 2,4-Dichlorophenoxyacetic Acid in Aqueous Systems by a Combination of Electrolytic and Photolytic Processes. Chemosphere, 44, 1223-1230. https://doi.org/10.1016/S0045-6535(00)00350-7

[14] Crini, G. (2006) Non-Conventional Low-Cost Adsorbents for Dye Removal: A Review. Bioresource Technology, 97, 1061-1085. https://doi.org/10.1016/j.biortech.2005.05.001

[15] Zaharia, C., Diaconescu, R. and Surpățeanu, M. (2007) Study of Flocculation with PONILIT GT-2 Anionic Polyelectrolyte Applied into a Chemical Wastewater Treatment. Open Chemistry, 5, 239-256. https://doi.org/10.2478/s11532-006-0057-6

[16] Wu, H., Wang, S., Kong, H., Liu, T. and Xia, M. (2007) Performance of Combined Process of Anoxic Baffled Reactor-Biological Contact Oxidation Treating Printing and Dyeing Wastewater. Bioresource Technology, 98, 1501-1504. https://doi.org/10.1016/j.biortech.2006.05.037

[17] Crini, G. and Badot, P.-M. (2008) Application of Chitosan, a Natural Aminopolysaccharide, for Dye Removal from Aqueous Solutions by Adsorption Processes Using Batch Studies: A Review of Recent Literature. Progress in Polymer Science, 33, 399-447. https://doi.org/10.1016/j.progpolymsci.2007.11.001

[18] Gupta, V., Carrott, P. and Ribeiro Carrott Suhas, M. (2009) Low-Cost Adsorbents: Growing Approach to Wastewater Treatment-A Review. Critical Reviews in Environmental Science and Technology, 39, 783-842. https://doi.org/10.1080/10643380801977610

[19] Ali, I. and Gupta, V. (2006) Advances in Water Treatment by Adsorption Technology. Nature Protocols, 1, 2661-2667. https://doi.org/10.1038/nprot.2006.370

[20] Zhu, H.-Y., Fu, Y.-Q., Jiang, R., Yao, J., Xiao, L. and Zeng, G.-M. (2012) Novel Magnetic Chitosan/Poly(vinyl alcohol) Hydrogel Beads: Preparation, Characterization and Application for Adsorption of Dye from Aqueous Solution. Bioresource Technology, 105, 24-30. https://doi.org/10.1016/j.biortech.2011.11.057

[21] Kyzas, G.Z., Travlou, N.A., Kalogirou, O. and Deliyanni, E.A. (2013) Magnetic Graphene Oxide: Effect of Preparation Route on Reactive Black 5 Adsorption. Materials, 6, 1360-1376. https://doi.org/10.3390/ma6041360

[22] Faraji, M., Yamini, Y., Tahmasebi, E., Saleh, A. and Nourmohammadian, F. (2010) Cetyltrimethylammonium Bromide-Coated Magnetite Nanoparticles as Highly Efficient Adsorbent for Rapid Removal of Reactive Dyes from the Textile Companies' Wastewaters. Journal of the Iranian Chemical Society, 7, S130-S144. https://doi.org/10.1007/BF03246192

[23] Ghaemi, M., Absalan, G. and Sheikhian, L. (2014) Adsorption Characteristics of Titan Yellow and Congo Red on $\mathrm{CoFe}_{2} \mathrm{O}_{4}$ Magnetic Nanoparticles. Journal of the Iranian Chemical Society, 11, 1759-1766. https://doi.org/10.1007/s13738-014-0448-0

[24] Ramalakshmi, S., Selvakumar, R., Muthuchelian, K. and Swaminathan, K. (2011) Utilization of Modified Gloriosa superba Waste as an Adsorbent for the Removal of Reactive Dyes from Aqueous Solutions. World Applied Sciences Journal, 15, 415-421.

[25] Mahmoodi, N.M., Arami, M., Limaee, N.Y., Gharanjig, K. and Ardejani, F.D. (2006) Decolorization and Mineralization of Textile Dyes at Solution Bulk by Heterogeneous Nanophotocatalysis Using Immobilized Nanoparticles of Titanium Dioxide. Colloids and Surfaces A: Physicochemical and Engineering Aspects, 290, 125-131. https://doi.org/10.1016/j.colsurfa.2006.05.012 
[26] Tan, K.B., Vakili, M., Horri, B.A., Poh, P.E., Abdullah, A.Z. and Salamatinia, B. (2015) Adsorption of Dyes by Nanomaterials: Recent Developments and Adsorption Mechanisms. Separation and Purification Technology, 150, 229-242. https://doi.org/10.1016/j.seppur.2015.07.009

[27] Dave, P.N. and Chopda, L.V.J. (2014) Application of Iron Oxide Nanomaterials for the Removal of Heavy Metals. Journal of Nanotechnology, 2014, Article ID: 398569.

[28] Hua, M., Zhang, S., Pan, B., Zhang, W., Lv, L. and Zhang, Q. (2012) Heavy Metal Removal from Water/Wastewater by Nanosized Metal Oxides: A Review. Journal of Hazardous Materials, 211, 317-331. https://doi.org/10.1016/j.jhazmat.2011.10.016

[29] Sadeghi, M., Irandoust, M., Khorshidi, F., Feyzi, M., Jafari, F., Shojaeimehr, T. and Shamsipur, M. (2016) Removal of Arsenic (III) from Natural Contaminated Water Using Magnetic Nanocomposite: Kinetics and Isotherm Studies. Journal of the Iranian Chemical Society, 13, 1175-1188. https://doi.org/10.1007/s13738-016-0832-z

[30] Hossain, M. and Iqbal, A. (2014) Production and Characterization of Chitosan from Shrimp Waste. Journal of the Bangladesh Agricultural University, 12, 153-160.

[31] Yuwei, C. and Jianlong, W. (2011) Preparation and Characterization of Magnetic Chitosan Nanoparticles and Its Application for $\mathrm{Cu}(\mathrm{II})$ Removal. Chemical Engineering Journal, 168, 286-292. https://doi.org/10.1016/j.cej.2011.01.006

[32] Cárdenas, G., Cabrera, G., Taboada, E. and Miranda, S.P. (2004) Chitin Characterization by SEM, FTIR, XRD, and ${ }^{13} \mathrm{C}$ Cross Polarization/Mass Angle Spinning NMR. Journal of Applied Polymer Science, 93, 1876-1885. https://doi.org/10.1002/app.20647

[33] de Alvarenga, E.S. (2011) Characterization and Properties of Chitosan. In: Elnashar, M., Ed., Biotechnology of Biopolymers, InTech, Rijeka.

[34] Czechowska-Biskup, R., Jarosińska, D., Rokita, B., Ulański, P. and Rosiak, J.M. (2012) Determination of Degree of Deacetylation of Chitosan-Comparision of Methods. Progress on Chemistry and Application of Chitin and Its Derivatives, 17, 5-20.

[35] Focher, B., Naggi, A., Torri, G., Cosani, A. and Terbojevich, M. (1992) Structural Differences between Chitin Polymorphs and Their Precipitates from Solutions-Evidence from CP-MAS ${ }^{13} \mathrm{C}-\mathrm{NMR}$, FT-IR and FT-Raman Spectroscopy. Carbohydrate Polymers, 17, 97-102. https://doi.org/10.1016/0144-8617(92)90101-U

[36] Zhao, D.-L., Wang, X.-X., Zeng, X.-W., Xia, Q.-S. and Tang, J.-T. (2009) Preparation and Inductive Heating Property of $\mathrm{Fe}_{3} \mathrm{O}_{4}$-Chitosan Composite Nanoparticles in an AC Magnetic Field for Localized Hyperthermia. Journal of Alloys and Compounds, 477, 739-743. https://doi.org/10.1016/j.jallcom.2008.10.104

[37] Xuan Nui, P., Tan Phuoc, N., Tuyet Nhung, P., Thi Thuy Nga, T. and Thi Van Thi, T. (2016) Synthesis and Characterization of Chitosan-Coated Magnetite Nanoparticles and Its Application in Curcumin Drug Delivery. Advances in Natural Sciences. Nanoscience and Nanotechnology, 7, Article ID: 045010.

[38] Chen, L., Tang, C.-Y., Ning, N.-Y., Wang, C.-Y., Fu, Q. and Zhang, Q. (2009) Preparation and Properties of Chitosan/Lignin Composite Films. Chinese Journal of Polymer Science, 27, 739-746. https://doi.org/10.1142/S0256767909004448

[39] Gregorio-Jauregui, K.M., Pineda, M.G., Rivera-Salinas, J.E., Hurtado, G., Saade, H., Martinez, J.L., Ilyina, A. and López, R.G. (2012) One-Step Method for Preparation of Magnetic Nanoparticles Coated with Chitosan. Journal of Nanomaterials, 2012, Article ID: 813958.

[40] Zandipak, R. and Sobhanardakani, S. (2016) Synthesis of $\mathrm{NiFe}_{2} \mathrm{O}_{4}$ Nanoparticles for 
Removal of Anionic Dyes from Aqueous Solution. Desalination and Water Treatment, 57, 11348-11360. https://doi.org/10.1080/19443994.2015.1050701

[41] Gao, H., Zhao, S., Cheng, X., Wang, X. and Zheng, L. (2013) Removal of Anionic Azo Dyes from Aqueous Solution Using Magnetic Polymer Multi-Wall Carbon Nanotube Nanocomposite as Adsorbent. Chemical Engineering Journal, 223, 84-90. https://doi.org/10.1016/j.cej.2013.03.004

[42] Faraji, M., Shabanian, M. and Aryanasab, F. (2018) Efficient Removal of Anionic Dyes from Aqueous Media Using Newly in Situ Synthesized Triazine-Based Nitrogen-Rich Network-Modified Magnetic Nanoparticles. Journal of the Iranian Chemical Society, 15, 733-741. https://doi.org/10.1007/s13738-017-1273-Z

[43] Zhang, Y.-R., Su, P., Huang, J., Wang, Q.-R. and Zhao, B.-X. (2015) A Magnetic Nanomaterial Modified with Poly-Lysine for Efficient Removal of Anionic Dyes from Water. Chemical Engineering Journal, 262, 313-318.

https://doi.org/10.1016/j.cej.2014.09.094

[44] Babu, B. and Ramakrishna, V. (2003) Modeling of Adsorption Isotherm Constants using Regression Analysis \& Neural Networks. Proceedings of 2nd International Conference on Water Quality Management, New Delhi, Paper No II-1.

[45] Arshadi, M., Faraji, A. and Mehravar, M. (2015) Dye Removal from Aqueous Solution by Cobalt-Nano Particles Decorated Aluminum Silicate: Kinetic, Thermodynamic and Mechanism Studies. Journal of Colloid and Interface Science, 440, 91-101. https://doi.org/10.1016/j.jcis.2014.10.040 